\title{
A different approach in removal of proximal Wharton's duct stone: Case report
}

\author{
Mahfuz Turan ${ }^{*}$, Huseyin Ozkan, Mehmet Fatih Garca, Hakan Cankaya, Koray Avcı, Nazım Bozan, \\ Ahmet Faruk Kıroglu
}

Department of Otorhinolaryngology, Yuzuncu Yil University Faculty of Medicine, Van, Turkey

\begin{abstract}
We aimed to approach with a different surgical technique to stone excision far from orifice in Wharton duct. A 51-year-old female patient admitted to our clinic with the complaints of pain and swelling at the right of mouth floor and especially swelling during nutrition at the inferior of right jaw. In the intra oral examination; a large, sensitive with palpation, sides are erythematous solid mass in the right submandibular canal region was detected. In the ultrasonography examination, left submandibular gland was found significantly heterogeneous and $1 \mathrm{~cm}$ in diameter hyperechoic posterior shade showing stone at approximately $10 \mathrm{~mm}$ distance to Wharton duct was visualized. Sialolithiasis treatment varies according to the localization of the stone, duration of the symptoms, frequency of repetition and size of the stone. Either conservative or surgical techniques can be used for treatment. Surgically, either intraoral or extraoral approaches can be used. In our case, after removing the stone from the distal part of Wharton duct, original orifice of the duct was deactivated and distal part of the duct was marsupialised to mouth floor. Saliva discharge was seen from the new orifice inside the mouth at the postoperative 3rd week of the case. More clinical studies with increased numbers of cases are needed for accurate results of the treatment method.
\end{abstract}

Key Words: Wharton's stone, proximal, surgery

\section{Introduction}

Salivary gland stones are the most common cause of salivary gland obstruction, cause obstruction at the same time and also have the potential of recurrence (1). They are more often seen in men between the ages of 30-60 years $(2,3)$. Although its reason still remains unclear, salivary gland stones generally develop unilaterally in major glands. They are more often localized in ducts or intra glandular ducts. Intra parenchymal sialolithes are rare. Sialolithes are met in submandibular gland as $80-85 \%$, in parotid gland $10-15 \%$ and in sublingual gland and minor salivary glands as $1-7 \%$ (4). Frequent occurrence of Submandibular sialolitiasis can be explained with its more viscous secretion, rich mucus, its duct is partly curled and its course is progressing from inferior towards superior direction, duct orifice is narrower than the duct and excess amount of organic matter in its content (4). They generally cause pain and swelling complaints before or during eating. Large sized stones can be palpated inside the duct (5). Although the most commonly used imaging techniques for the diagnosis of sialolithes are occlusive and panoramic graphs, ultrasonography (US) and sialography; recently can be benefited from computerized tomography (CT), magnetic resonance sialography and sialoendoscopy methods too (6). While transoral approach is preferred for the treatment of the stones observed close to the perihilar region of the gland or mouth floor, submandibular gland excision treatment is used for the stones inside proximal duct or parenchyma (7). We aimed to approach with a different surgical technique to stone excision far from orifice in Wharton duct.

\section{Case report}

A 51-year-old female patient admitted to our clinic with the complaints of pain and swelling at the right of mouth floor and especially swelling during nutrition at the inferior of right jaw. In the intraoral examination; a large, sensitive with palpation, sides are erythematous solid mass in the right submandibular canal region was detected. There wasn't any purulent discharge seen with the patting of right submandibular gland. In the diagnostic ultrasonography; left submandibular gland was significantly heterogeneous, and $1 \mathrm{~cm}$ in diameter hyperechoic posterior shade showing stone at approximately $10 \mathrm{~mm}$ distance to Wharton duct was detected. In neck CT, there was

*Corresponding Author: Mahfuz Turan, MD., Yuzuncu Yil University, Faculty of Medicine, Department of Otorhinolaryngology, 65080, Van, Turkey, Tel: +90 (432) 21504 73, Fax: +90 (432) 21675 19, E-mail: mahfuzturan@hotmail.com Received: 15.03.2016, Accepted: 05.04.2016 
increase of right submandibular gland sizes and contrast enhancement rates than left visualized (inflammation); approximately $1 \times 1 \mathrm{~cm}$ sized calculi visualized at submental region right half compatible with sialolithiasis (Figure 1). Under local anesthesia, incision was performed with transoral approach to the mucosa on submandibular duct, mucosal and submucosal structures were passed through and the duct was identified, the stone was reached with blunt dissection, the stone was approximately $10 \mathrm{~mm}$ away from the Wharton duct orifice (Figure 2). The stone was carefully caught with puch and removed (Figure 3). The duct was then irrigated with normal saline to clean the region and to remove stone debris. The incised mucosa of the mouth floor was then sutured back without

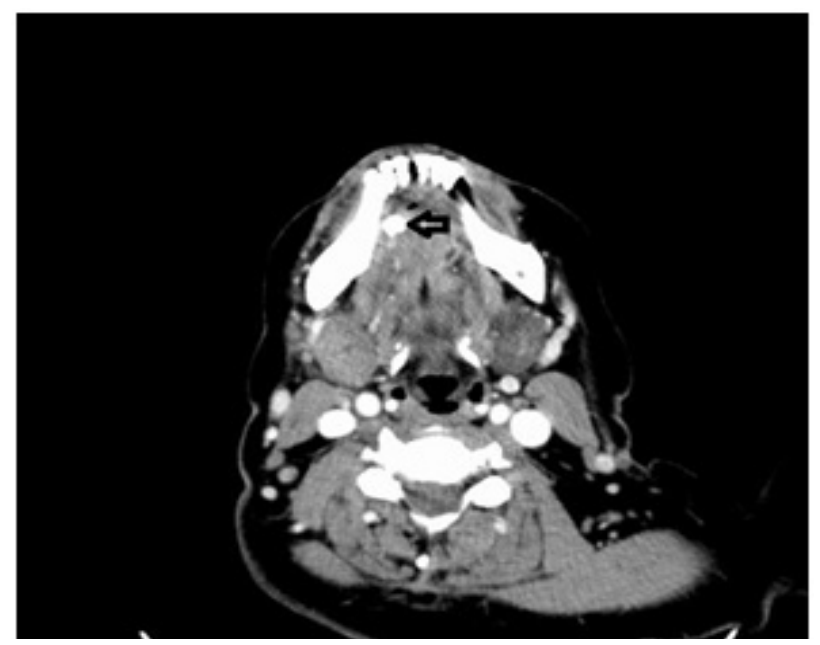

Fig. 1. The arrow shows the stone in Wharton duct in CT.

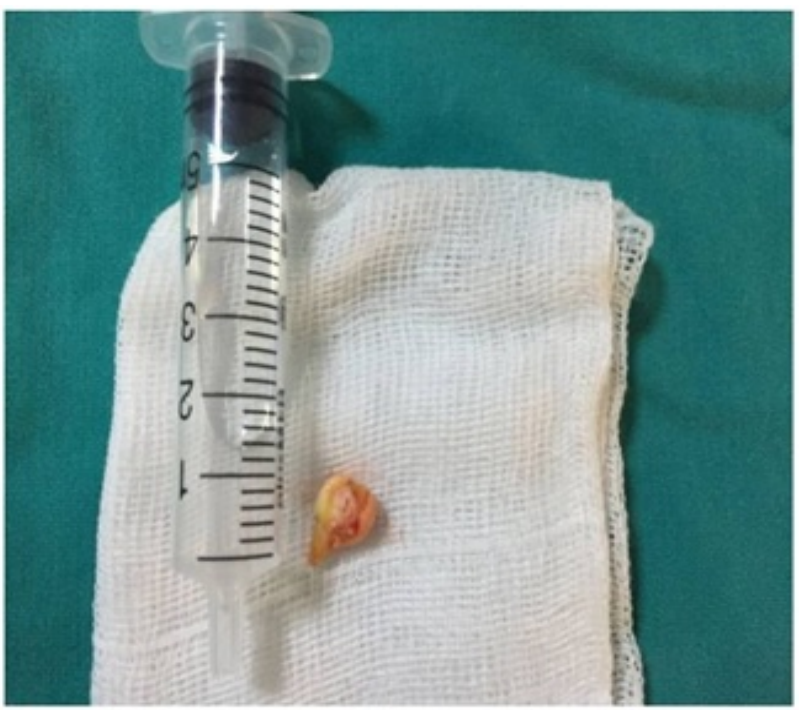

Fig. 3. The stone removed from Wharton duct is visualized. repairing the incision site of Wharton's duct (marsupialization). The patient was discharged the next day. Analgesics and antiseptic gargle were prescribed to the case. On the $21^{\text {st }}$ postoperative day of the case, a new and functional orifice opening to the mouth floor right lateral part was seen (Figure 4).

\section{Discussion}

Etiology and pathogenesis of salivary gland stones is still not understood generally (8). The severity of pain and swelling in salivary gland stones are related to the intra-duct pressure and the salivary flow varies according to the obstruction level. In our case, pain and swelling complaints were the most prominent. Salivary gland stones larger than

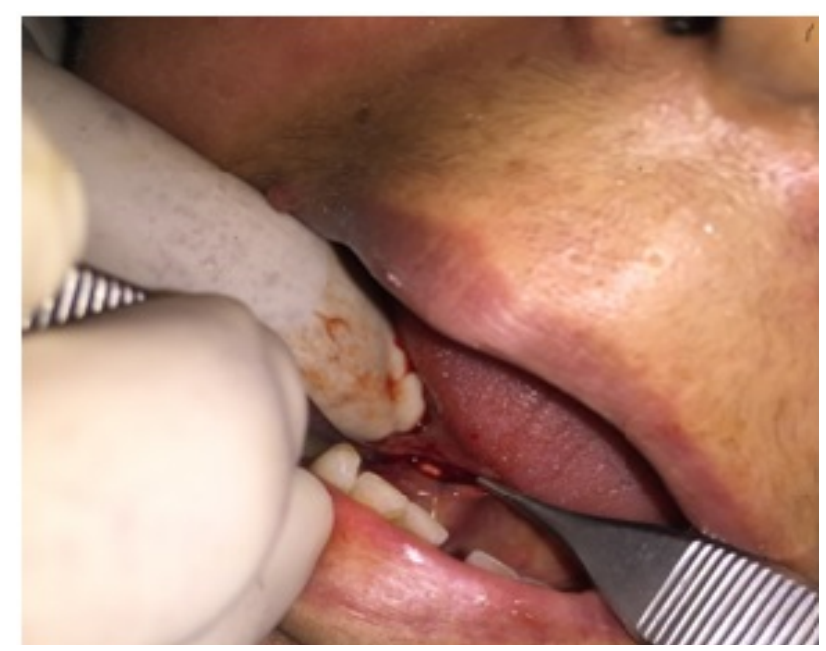

Fig. 2. Intraoperative stone in Wharton duct is seen.

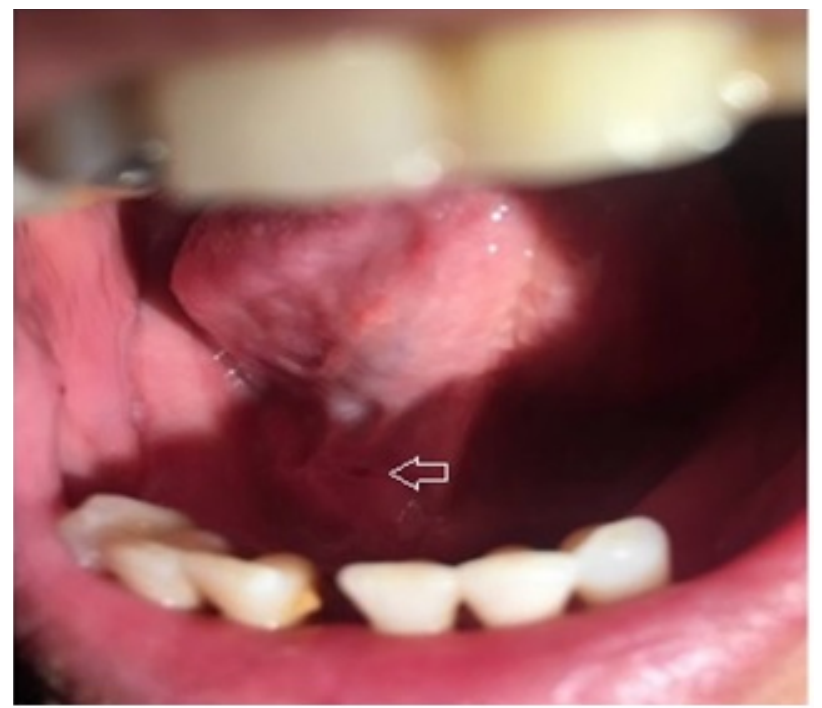

Fig. 4. The arrow shows the new orifice opening to the mouth floor right lateral part. 
$1 \mathrm{~cm}$ are rare. Most of the salivary gland stones are radiopaque and can be visible in direct radiographs. The reason is these stones comprises of calcium carbonate and calcium phosphate. Non opaque stones comprise urate. Sialolithes can be identified well in panoramic and periapical radiographs. In case of multiple stones and/or when their positions cannot be clearly detected with routine radiographs; sialography, ultrasound, sialoendoscopy, CT and magnetic resonance sialographies can be helpful for diagnosis (6). In our case, we were benefited from ultrasonography and CT examinations to verify the clinical examination. Submandibular stones are classified in two groups as anterior (those remaining front of this line) and posterior (those remaining behind this line) according to their relationship with mandibular first molar at transverse direction. Anterior stones can be easily imaged with mandibular oclusal radiograph and can be easily excised since they are opened into mouth. Small stones those not opened into mouth can be removed from ductal opening following the dilation of orifice. Posterior stones on the other hand, located in the gland hilus or inside the gland. For this reason, the stone may remain unnoticed with intraoral palpation in most of the cases.

Excision of the stone and submandibular gland with extraoral approach may be needed. Treatment of sialolithiasis varies according to the location of stone, duration of symptoms, frequency of recurrence and the size of the stone (9). In submandibular gland stones; primarily conservative treatment for the small ones (plenty of hydration, hot application and massaging the gland etc.) can be helpful. Submandibular gland (SMG) resection is applied in cases that salivary glands permanently damaged secondary to saliva stasis, infection and/or recurrent gland diseases (10). However, iatrogenic injuries are higher in SMG resection than the other methods. 3\% permanent paralysis and 10\% temporary paralysis of the facial nerve marginal mandibular branch was reported (11). Lingual and hypoglossal nerve injury is reported as $4 \%$ and approximately half of these injuries were expressed to be permanent paralysis (13). Another disadvantage is unwanted skin incision scar (11).

Recently minimal invasive methods were defined such as extracorporeal lithotripsy, interventional radiology and operative sialoendoscopy $(12,13)$. Although these new techniques provide severe benefit to the diagnosis of large salivary gland stones, they may still remain insufficient especially for the treatment of large stones (14). Since almost half of the submandibular gland stones are localized at the distal $1 / 3^{\text {rd }}$ part of the duct, they can be easily removed surgically with an incision performed to mouth floor. Stones which are located further back can be removed following opening the orifice of the duct with lacrimal probes or dilators. Stones located $1-2 \mathrm{~cm}$ posterior to orifice are removed by performing an incision parallel to the longitudinal axes of the duct with trans oral approach (15). In our case intraoral approach was preferred since the stone was at $1 \mathrm{~cm}$ distance to Wharton duct orifice. Zenk et al. (7) have reported that stones are removed successfully with intraoral approach and incision of the duct just above the stone. This is a simple surgical procedure and there is low morbidity; However, recurrence was reported in few patients in postoperative period (16). Eun et al. (14) have reported in their study that they have removed the proximal Wharton duct stones and the incised mucosa of the mouth floor was then sutured back without repairing the incision site of Wharton's duct method and this method has important advantages than conventional submandibular gland excision. Since they avoided lingual nerve manipulation with this method, it has advantages such as absence of sensitive complaints in tongue and mouth floor and, shorter hospitalization duration and shorter duration of operation and they also reported less pain and less severe complication than conventional SMG resection. It is sufficient to suture the incision edges after removing the stone. There is no need of hesitation for salivary fistulas may develop on incision. If the surgeon performing this application wishes, can marsupialise the suture edges to mouth floor mucosa (14).

Iqbal et al. (17) have reported that after removal of stone in Wharton duct, they intraorally marsupialise the opening in the duct and create a 2 $\mathrm{cm}$ sized opening. They have reported that this opening reduced up to $3 \mathrm{~mm}$ after postoperative $45^{\text {th }}$ day however the opening is sufficient. In our case, after the stone palpated at the mouth floor was removed via intraoral approach, the duct was not repaired; a new orifice was created by marsupialising the incised part of the duct to mouth floor. In postoperative period there wasn't any sensory and taste loss inside the mouth and tongue observed. Also we observed the new orifice was open and there was saliva flow inside it.

We did not encounter any complications in our case with rarely applied marsupialising of incision 
edges to mouth floor and observed new orifice that is opening to the right lateral part of the mouth floor is functional in postoperative period. Marsupialising the duct to mouth floor procedure can be used for the proximally located stone cases inside the duct. More clinical studies with increased numbers of cases are needed for accurate results of the treatment method.

\section{References}

1. Zenk J, Benzel W, Iro H. New Modalities in the Management of Human Sialolithiasis. Minimally Invasive Therapy 1994; 3: 275-284.

2. Chu DW, Chow TL, Lim BH, Kwok SPY. Endoskobik manangement of submandibuler sialolitiazis.Surg Endosc 2003; 17: 876-879.

3. Austin T, Davis J, Chan T. Sialolitiazis of submandibuler gland. J Emerg Med 2004; 26: 221-223.

4. Huoh KC, Eisele DW. Etiologic factors in sialolithiasis. Otolaryngol Head Neck Surg 2011; 145: 935-939.

5. Williams MF. Sialolithiasis. Otolaryngol Clin North Am 1999; 32: 819-834.

6. Huang TC, Dalton JB, Monsour FN, et al. Multiple, large sialoliths of the submandibular gland duct: a case report. Aust Dent J 2009; 54: 61-65.

7. Zenk J, Constantinidis J, Al-Kadah B, et al. Transoral removal of submandibular stones. Arch Otolaryngol Head Neck Surg 2001; 127: 432-436.

8. Soares LP, Gaião de Melo L, Pozza DH, Pinheiro AL, Gerhardt de Oliveira M. Submandibular Gland Sialolith in a Renal Transplant Recipient: A
Case Report. J Contemp Dent Pract 2005; 6: 127 133.

9. Takeda Y, Oikawa Y, Satoh M, Nakamura S. Sialolith of the Submandibular Gland with Bone Formation. Pathol Int 2003; 53: 309-312.

10. McGurk M, Esudier M. Removing salivary gland stones. Br J Hosp Med 1995; 54: 184-185.

11. McGurk M, Makdissi J, Brown JE. Intra-oral removal of stones from the hilum of the submandibular gland: report of technique and morbidity. Int J Oral Maxillofac Surg 2004; 33: 683-686.

12. Zenk J, Bozzato A, Winter M, Gottwald F, Iro H. Extracorporeal shock wave lithotripsy of submandibular stones: evaluation after 10 years. Ann Otol Rhinol Laryngol 2004; 113: 378-383.

13. Ottaviani F, Capaccio P, Campi M, Ottaviani A. Extracorporeal electromagnetic shock wave lithotripsy for salivary gland stone. Laryngoscope 1996; 106: 761-764.

14. Eun YG, Chung DH, Kwon KH. Advantages of intraoral removal over submandibuler gland resection for proximal submandibuler Stones:a prospective randomized study. Laryngoscope 2010; 120: 2189-2192.

15. Siddiqui SJ. Sialolithiasis: An Unusually Large Submandibular Salivary Stone. British Dental Journal 2002; 193: 89-91.

16. Roh JL, Kim AY. Application of mitomycin C after transoral removal of submandibular stones and sialodochoplasty. Laryngoscope 2005; 115 : 915-918.

17. Iqbal A, Gupta AK, Natu SS, Gupta AK. Unusually large sialolith of Wharton's duct. Ann Maxillofac Surg 2012; 2: 70-73. 